\title{
Fathering of a child with the assistance of electroejaculation in conjunction with intracytoplasmic sperm injection: case report
}

\author{
Masashi Yamamoto ${ }^{1}$, Hitoshi Momose ${ }^{2}$ and Kaoru Yamada ${ }^{1}$ \\ ${ }^{1}$ Department of Urology, Hoshigaoka Koseinenkin Hospital, 4-8-1 Hoshigaoka, Hirakata, Osaka 573 Japan, and \\ ${ }^{2}$ Department of Urology, Nara Medical University, 840 Shijyo-cho, Kashihara, Nara 634, Japan
}

\begin{abstract}
Ejaculatory failure and poor fertility are major problems for patients with spinal cord injury, who wish to father children. Artificial ejaculation in conjunction with assisted reproductive techniques has been proposed as a possible solution to this situation. In this paper, we presented the case of a tetraplegic man who fathered a child with the aid of electroejaculation with intracytoplasmic sperm injection (ICSI).
\end{abstract}

Keywords: spinal cord injury; electroejaculation; intracytoplasmic sperm injection; healthy live birth

\section{Case report}

A 38-year-old man was referred to our clinic to discuss the means whereby he could father a child. He had a C5 complete tetraplegia of 16 years' duration. His wife was 32 years old and was healthy. Using a Seager NRH Model 12 (G\&C Instrument Co., National Rehabilitation Hospital, Washington, DC, USA), in December 1991, he underwent the first attempt of electroejaculation but this was antegrade. After repeated preliminary electroejaculations for the assessment of semen quality, artificial insemination of the husband (AIH) was performed 11 times but without success (Figure 1). Low motility of the semen was considered to be the cause for these failures and thus he was sent to the Advanced Fertility Center, Fuchu Hospital for ICSI. In February 1995, the first attempt of a combined therapy with electroejaculation and ICSI was conducted. Pregnancy was achieved and a healthy boy at fullterm was born in October 1995. Analysis of the immediate semen sample indicated $39 \times 10^{6} / \mathrm{ml}$ with $5 \%$ motility.

\section{Discussion}

Most male patients with severe spinal cord injury have fertility problems by ejaculatory failure and poor quality of semen. ${ }^{1,2}$ Artificial ejaculation, such as electroejaculation, ${ }^{1-4}$ vibratory stimulation $^{5,6}$ and intrathecal chemical ejaculation ${ }^{7}$ have been used to obtain semen from such men. Electroejaculation is a safe and effective means of obtaining semen from them. Electroejaculation has been conducted in our Institutes on 53 patients with severe spinal cord injury. Ten had cervical, 37 thoracic and six lumbar paraplegia, with a mean patient age of 31 years (range 19 to 47) and a

Correspondence: M Yamamoto mean duration after injury of 10 years (range 1 to 38 ). Antegrade ejaculation was achieved in 46 patients $(86.8 \%)$. The volume of the ejaculate ranged from 0.05 to $5.2 \mathrm{ml}$ (average $1.3 \mathrm{ml}$ ) and sperm concentration from 0 to $546 \times 10^{6} / \mathrm{ml}$ (average $\left.71.9 \times 10^{6} / \mathrm{ml}\right)$. Sperm motility was poor ( 0 to $68 \%$, average $17.2 \%$ ). It has been consistently recognized that semen obtained from spinal cord injury men by the present technique show poor sperm motility. ${ }^{1,8}$ Pregnancy rates are thus low despite high induction rates of ejaculation by electroejaculation. The first healthy live birth after electroejaculation was reported by Francois and associates in 1978. ${ }^{9}$ The authors have attempted AIH on 54 occasions for 11 couples and reported the first two

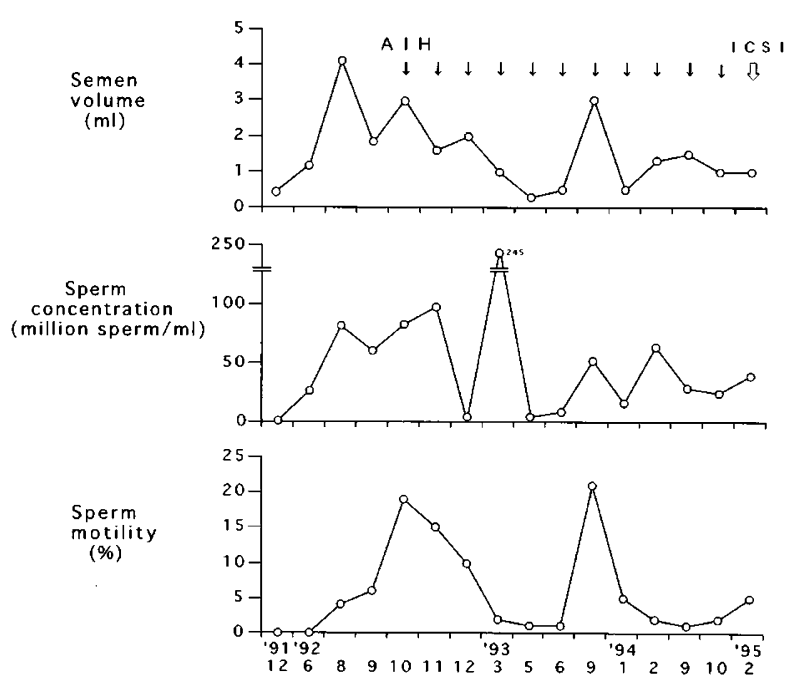

Figure 1 Changes in the results of sperm analyses of the patient. AIH ( $\downarrow)$ was attempted 11 times. ICSI ( $)$ in February 1995 resulted in pregnancy 
cases of spinal cord injury men fathered children by electroejaculation in Japan. ${ }^{1}$

Pregnancy can be effectively achieved by advanced reproductive technology (ART) such as in vitro fertilization - embryo transfer (IVF-ET), zygote intrafallopian transfer, gamete intrafallopian transfer, subzonal insemination and ICSI, even if few motile sperm are made available by electroejaculation. Since Ayers and associate ${ }^{10}$ achieved the first live birth by electroejaculation combined with IVF-ET in 1988, several pregnancies have resulted from a combination of electroejaculation and ART, resulting in healthy live births. ${ }^{1-14}$ However, there are few reports of a combination of electroejaculation and ICSI. ${ }^{15}$ The present case is considered to be the first successful example in Japan of a tetraplegic man fathering a child by means of electroejaculation in conjunction with ICSI.

\section{Conclusions}

Artificial ejaculation conducted with advanced reproductive technology is the optimal means for patients with a severe spinal cord injury who wish to have children.

\section{Acknowledgements}

The authors express their appreciation to Drs Shinzo Isojima, Shin-ichiro Kobayashi, Hiroshi Kato, and Masahumi Handa, Advanced Fertility Center, Fuchu Hospital for processing ICSI.

\section{References}

1 Momose $\mathrm{H}$ et al. Electroejaculation in patients with spinal cord injury: First report of a large scale experience in Japan. Int J Urol 1995; $2: 326-329$.
2 Bennett CJ, Seager SW, Vasher EA, McGuire EJ. Sexual function and electroejaculation in men with spinal cord injury: review. J Urol 1988; 139: 453-457.

3 Munro D, Horne HW, Paull DP. The effect of injury to the spinal cord and cauda equina on the sexual potency of men. New Engl J Med 1948; 239: $903-911$.

4 Halstead LS, VerVoort S, Seager SWJ. Rectal probe electroejaculation of anejaculatory spinal cord injured men. Paraplegia 1987; 25: $120-129$.

5 Brindley GS. Reflex ejaculation under vibratory stimulation in paraplegic men. Paraplegia 1981; 19: 299-302.

6 Beckermann H, Be Cher J, Lankhorst GJ. The effectiveness of vibratory stimulation in anejaculatory men with spinal cord injury. Review article. Paraplegia 1993; 31: 689-699.

7 Guttmann L, Walsh JJ. Prostigmin assessment test of fertility in spinal man. Paraplegia 1971; 9: 39-51.

8 Buch JP, Zorn BH. Evaluation and treatment of infertility in spinal cord injured men through rectal probe electroejaculation. J Urol 1993; 149: 1350 - 1354.

9 Francois $\mathrm{N}$ et al. Electroejaculation of a complete paraplegic followed by pregnancy. Paraplegia 1978; 16: 248.

10 Ayers JWT et al. Successful combination therapy with electroejaculation and in vitro fertilization-embryo transfer in the treatment of a paraplegic male with severe oligoasthenospermia. Fertil Steril 1988; 49: 1089 - 1090.

11 Randolph JF Jr et al. Combined electroejaculation and in vitro fertilization in the evaluation and treatment of anejaculatory infertility. J IVF Embryo Trans 1990; 7: 58-62.

12 Leeton J, Yates C, Rawicki B. Successful pregnancy using known donor oocytes fertilized in vitro by spermatozoa obtained by electro-ejaculation from a quadriplegic husband. Hum Reprod 1991; 6: $384-385$.

13 Hill DL, Kuyt F, Vogel M, Kaplan C. Delivered twins from electroejaculation and tubal embryo transfer. J IVF Embryo Trans 1991; 8: $296-298$.

14 Toledo AA et al. Electroejaculation in combination with in vitro fertilization and gamete micromanipulation for treatment of anejaculatory male infertility. Amer J Obst Gynec 1992; 167: $322-326$

15 Matthews GJ, Gardiner TA, Eid JF. In vitro fertilization improves pregnancy rates for sperm obtained by rectal probe ejaculation. J Urol 1996; 155: $1934-1937$. 